Rabaska

Revue d'ethnologie de l'Amérique française

\title{
LAFORTE, CONRAD. Contes scatologiques de tradition orale. Illustrations de Béatrice Laforte. Québec, Éditions Va bene, "Menteries drôles et merveilleuses ", 2003, 187 [1] p. ISBN 2-89518-150-0
}

\section{Donald Deschênes}

Volume 2, 2004

URI : https://id.erudit.org/iderudit/201670ar

DOI : https://doi.org/10.7202/201670ar

Aller au sommaire du numéro

Éditeur(s)

Société québécoise d'ethnologie

ISSN

1703-7433 (imprimé)

1916-7350 (numérique)

Découvrir la revue

Citer ce compte rendu

Deschênes, D. (2004). Compte rendu de [LAFORTE, CONRAD. Contes scatologiques de tradition orale. Illustrations de Béatrice Laforte. Québec,

Éditions Va bene, « Menteries drôles et merveilleuses ", 2003, 187 [1] p. ISBN

2-89518-150-0]. Rabaska, 2, 223-225. https://doi.org/10.7202/201670ar d'utilisation que vous pouvez consulter en ligne.

https://apropos.erudit.org/fr/usagers/politique-dutilisation/ 
Laforte, ConRad. Contes scatologiques de tradition orale. Illustrations de Béatrice Laforte. Québec, Éditions $V a$ bene, "Menteries drôles et merveilleuses », 2003, 187 [1] p. ISBN 2-89518-150-0.

Il y a longtemps que Conrad Laforte projetait de consacrer un recueil aux contes scatologiques qu'il avait recueillis, notamment au Saguenay-LacSaint-Jean et dans les Cantons de l'Est. Cet ouvrage est le fruit d'un travail rigoureux. Il y a rassemblé quelque trente-cinq contes dont six contes merveilleux, deux contes romanesques, un conte du diable stupide et quatorze contes facétieux. Les autres, non catalogués, tiennent de l'anecdote et du 
conte facétieux. Ce répertoire va des courtes blagues comme « Le Pet avec une peau », " La Statue qui chie » ou « La Pilule de marde », jusqu'aux contes merveilleux tels que «La Princesse mariée à un corbeau " et "Les Trois Lapins » ou au conte de l'âme vendue au diable comme « Le Diable embêté ». Ces contes proviennent d'une quinzaine de conteurs dont Mme Grégoire Côté, née Mélanie Houde, et le volubile Ernest Gagné que l'auteur nous avait fait connaître et apprécier dans Menteries drôles et merveilleuses. Contes traditionnels du Saguenay (Montréal, Quinze, Mémoires d'homme, 1978).

Si la diversité du répertoire fait la richesse de ce recueil, cet intérêt réside également dans la nature et le propos même de ces contes. Ces contes et blagues sont scatologiques à n'en point douter, on ne peut plus brun par moments, tout particulièrement dans le dernier conte, «La Femme qui ne mange pas ». Ils illustrent la transgression d'un interdit. Par contre, si on se moque allègrement des fonctions d'élimination du corps, on y aborde, cependant, la sexualité humaine avec beaucoup de réserve et un respect certain de la fonction de reproduction; un trait qui était aisément observable de l'humour traditionnel canadien-français. Tout au plus, le conteur dira : «Ils se sont couchés et ils ont fait leur petite affaire », sans plus, avec très peu de double sens et sans jamais faire allusion aux organes sexuels. Ce qui en rend d'ailleurs la lecture beaucoup moins rebutante qu'il n'y paraîtrait au départ. La verve et l'humour des conteurs de Conrad Laforte ne sont pas sans nous rappeler la belle truculence de Rabelais et confirment, encore une fois, à ce propos, notre lien inaltérable avec le moyen âge français. La libération des mœurs a permis de mettre au jour, et de sortir de l'enfer, tout un répertoire que les folkloristes, par autocensure, se sont parfois privés de publier, leur tâche n'étant pas de bousculer, mais de conserver et de comprendre.

De toute évidence, la collection "Menteries drôles et merveilleuses » prend la relève de la très belle collection « Mémoires d'hommes » des Quinze éditeurs, mais dans un format plus économique. À la fin de l'ouvrage, on trouve un lexique, qui est davantage un glossaire, lacunaire. Les informations sur chacun des mots et expressions sont minimales, voire incomplètes. S'agitil d'un nom, d'un verbe, d'un adjectif, de la déformation d'un mot (par exemple, mautadit et batêche pour maudit et baptême)? Quelle est son origine? sa prononciation (par exemple, moses se prononce-t-il moze ou mosesse, ou mosusse) ? Aussi, il eut été nécessaire que les termes et expressions composant le lexique apparaissent en italique dans le texte. De nombreux autres mots et expressions auraient dû se retrouver dans ce glossaire, comme abrier, bâdrer, butin, crimer une tape, fifteen, fourchicane ou sport (prononcé à l'anglaise et utilisé comme adjectif). Enfin, quelques problèmes de ponctuation relatifs à l'utilisation de la virgule et de transcription demandent 
un effort de compréhension de la part du lecteur. Outre ce lexique, un index des types selon la classification d'Aarne-Thompson complète bien l'ouvrage.

Les Contes scatologiques de tradition orale de Conrad Laforte viennent, pour le chercheur, combler un vide important et, pour le lecteur, lui assurer un moment de lecture tout à fait agréable et, même, hilarante. Il faut espérer que l'auteur continuera à nous faire partager ses riches cueillettes ethnographiques et ainsi contribuer à en conserver la mémoire.

Donald Deschênes

Société québécoise d'ethnologie, Québec 